\title{
Descentralización y participación en América Latina: Una mirada desde la economía
}

\section{Iván Finot \\ Dirección de Gestión Local \\ y Regional \\ Instituto Latinoamericano \\ y del Caribe \\ de Planificación Económica \\ y Social (ILPES)/ \\ Comisión Económica \\ para América Latina \\ y el Caribe (CEPAL) \\ ifinot@eclac.cl}

Para que la descentralización política favorezca la eficiencia se requeriría que el gasto local estuviera vinculado con los respectivos esfuerzos fiscales, y que los procesos (locales) a través de los cuales se adoptan decisiones sobre provisión de bienes públicos fueran al menos tan democráticos como los centrales. En América Latina pocas veces se cumplen esas condiciones básicas. Esto se debería principalmente a que los procesos de descentralización se han orientado sobre todo al cumplimiento de objetivos sociales. Hoy, sin embargo, sería imperativo acrecentar la autonomía de los ámbitos subnacionales para potenciar la competitividad económica. En este artículo se analiza cómo podría lograrse este nuevo objetivo sin descartar y más bien creando sinergias respecto a otros, tales como estimular la participación ciudadana, reducir inequidades sociales y territoriales, y hacer más eficiente el aparato estatal —incluido el ámbito fiscal— para lograr estos objetivos estratégicos. 


\section{I}

\section{Introducción}

Así como hasta la crisis de la deuda la tendencia predominante en América Latina era centralizar en los gobiernos nacionales tanto las decisiones políticas como las económicas, con la democratización y el ajuste que la crisis requirió, en los años 80 se inició una tendencia histórica a traspasar parte de la provisión de bienes públicos hacia procesos democráticos subnacionales (descentralización política) y a transferir procesos de producción de los bienes provistos públicamente a la competencia económica (descentralización económica). ${ }^{1}$

De la descentralización política se esperaba que contribuyera en forma decisiva a suscitar una participación constructiva, a aumentar la eficiencia de la gestión pública y a lograr una mayor equidad territorial y social. Sin embargo, después de más de diez años de iniciados los procesos más antiguos de la región, los avances en participación son dispares, aún no se observan resultados concluyentes en cuanto a eficiencia y el ingreso geográfico bruto se sigue concentrando en algunos territorios. Se ha logrado aumentar la cobertura de servicios sociales pero en muchos casos se acentúan las diferencias interterritoriales. Los sistemas de transferencias adoptados no propician la eficiencia fiscal (Finot, 1996) y el excesivo endeudamiento de los gobiernos subnacionales habría generado desequilibrios macroeconómicos (CEPAL, 1998). Así como inicialmente la descentralización concitó grandes esperanzas, contemporáneamente ha surgido una desconfianza sobre su efectividad, lo que puede llegar a comprometer avances del proceso democratizador que sólo pueden ser viabilizados a través de la descentralización política. Se hace indispensable entonces indagar por qué no se están logrando plenamente los objetivos de la descentralización, a fin de poder dis-

$\square$ Este artículo fue elaborado, en una versión inicial, al calor de una presentación y una estimulante discusión, en varias sesiones, con todos los profesionales del ILPES. El autor agradece a sus colegas por el interés, los cuestionamientos y los aportes brindados en aquella oportunidad, y también al juez anónimo que leyó este trabajo en una versión anterior como requisito previo para que fuera publicado, cuyas observaciones y sugerencias fueron muy valiosas para mejorarlo.

${ }^{1}$ Ver la justificación de esta diferenciación en el marco conceptual que se desarrolla como primer punto de este trabajo. cernir algunos lineamientos que permitan superar los problemas y poder reimpulsar los procesos.

El ILPES se impuso esta tarea por mandato de sus gobiernos miembros. Sin desconocer que los procesos de descentralización son, en esencia, políticos, se realizó un análisis económico ${ }^{2}$ de aquellos que fueron emprendidos en la región durante el decenio de 1980, a fin de proporcionar elementos de reflexión desde este punto de vista, algunos de cuyos resultados fueron presentados en la X Reunión de Ministros y Jefes de Planificación (ILPES, 1998). En aquella oportunidad ya se señalaba la conveniencia de diferenciar entre aquellas funciones que los gobiernos subnacionales realizan como cabezas de autonomías y aquellas otras que efectúan como agentes de los respectivos gobiernos centrales, lo que conduciría a una transformación de los actuales sistemas de transferencias. En el presente artículo, elaborado a partir de aquellos avances y de otros trabajos del autor - principalmente Finot, 1996 y 2001 - , se profundiza el marco conceptual en que se basan esas propuestas (el "federalismo fiscal"), ${ }^{3}$ se focaliza en los problemas que dicho marco permite detectar y se avanza en las modificaciones que sería necesario realizar en los procesos de descentralización, no sólo para alcanzar los objetivos ya trazados en condiciones de sostenibilidad financiera, sino en función de uno nuevo: hacer más competitivas a las economías de la región.

\section{Las condiciones de eficiencia}

\section{a) Dos tipos de asignación}

Existe consenso en que, de las tres funciones económicas fundamentales del Estado (estabilización, dis-

\footnotetext{
2 Principalmente a partir de la información generada por un proyecto regional CEPAL/GTZ sobre Descentralización Fiscal, ejecutado entre 1994 y 1997, cuya coordinación estuvo a cargo de Gabriel Aghón (†).

3 Así se denomina en la literatura a la teoría económica de la descentralización, cuyos primeros elementos pueden ser encontrados en Ostrom, Tiebout y Warren (1961). Oates (1977), quien acuñó el término de "federalismo fiscal", lamenta en un artículo relativamente reciente (Oates, 1999) no haber denominado a esta rama especializada "teoría de la descentralización”. En efecto, el término "federalismo" ha contribuido a circunscribir estos valiosos análisis a los casos de los países federales, cuando resultan de especial utilidad si se aplican al análisis de la descentralización hasta niveles muy próximos al ciudadano.
} 
tribución y asignación), la que conviene descentralizar es esta última. La función de asignación se refiere principalmente a decisiones sobre provisión de bienes públicos: qué bienes, cuánto de cada uno de ellos y con qué parte del ingreso - actual y futuro - proveerlos públicamente. Sin embargo estas determinaciones, que se adoptan principalmente a través de la aprobación de presupuestos, también incluyen decisiones sobre qué se comprará y qué se producirá directamente, y, en lo que se refiere a esto último, con qué combinación de factores e insumos se lo hará, es decir, cómo producir. Las decisiones políticas sobre asignación se refieren entonces a dos tipos de asignación: una sobre provisión, donde se define principalmente qué y con qué recursos se proveerá, y otra sobre producción, en que se decide cómo se producirá aquello que se proveerá.

\section{b) Asignación y eficiencia}

La provisión de bienes públicos ${ }^{4}$ corresponde, por definición, a soluciones cooperativas ${ }^{5}$ y se realiza a través de procesos democráticos que, para servir como mecanismos eficientes de revelación de preferencias, deben vincular el gasto con los aportes para financiarlo (Musgrave y Musgrave, 1992). Como toda solución cooperativa, una provisión pública no corresponde a ninguna preferencia individual sino, en el mejor de los casos, a una suma de preferencias ciudadanas (Samuelson, 1954), pero se justifica cuando a través de ella la comunidad en su conjunto está mejor que si no hubiera tal solución. La demanda de bienes públicos varía según el ámbito de consumo de cada uno de ellos: desde aquellos casos en que trasciende las fronteras nacionales — como lo serían los generados por procesos de integración o, incluso, bienes públicos globales, tales como los tribunales internacionales para juzgar crímenes de guerra - hasta aquellos otros que son provistos para ser utilizados principalmente por pequeñas comunidades rurales o urbanas. Entonces, siguiendo el razonamiento del teorema de la descentralización (Oates, 1977), la provisión de bienes públicos será tanto más eficiente cuanto mejor se adecue a la demanda - territorialmente diferenciada — de dichos bienes. ${ }^{6}$

\footnotetext{
${ }^{4}$ Bienes públicos: en principio, normas, servicios y bienes económicos provistos por las organizaciones del Estado, de cuyo consumo ningún ciudadano puede ser excluido.

${ }^{5}$ Opción por la solución pública o colectiva (public choice), por oposición a privada o individual. Sobre este enfoque, véase Mueller (1984). ${ }^{6}$ Básicamente, porque los consumidores pueden "votar con los pies", según lo expresara Tiebout (1956), en busca del territorio que mejor responda a sus preferencias de bienes públicos, lo que introduce la competencia entre territorios (incluidos países).
}

Esta diferenciación se expresa efectivamente cuando los ciudadanos deciden sobre la parte de su ingreso que están dispuestos a entregar para financiar distintas soluciones correspondientes a diferentes ámbitos.

Para adecuar mejor la provisión de bienes públicos a las diversas preferencias ciudadanas sería conveniente entonces que, una vez definido qué será provisto privativamente por el nivel nacional (las preferencias nacionales), se aproximara el aparato estatal lo más posible al ciudadano, se definieran varios niveles de decisión sobre provisión y que ésta se distribuyera entre esos niveles por exclusión, como un proceso de abajo hacia arriba. Se debería, además, estimular la búsqueda de soluciones cooperativas entre comunidades territoriales de un mismo nivel, antes que recurrir a soluciones centralizadas en el nivel superior. Este criterio de eficiencia económica coincide con el principio político de la subsidiariedad, lo que refleja el gran potencial de la descentralización política para profundizar la democratización.

En cuanto a cómo producir los bienes a proveer, mientras en el caso de la provisión privada en competencia ésta obliga a los productores a buscar la combinación de factores e insumos que les implique un menor costo, la provisión de bienes públicos es básicamente monopólica $;{ }^{7}$ además, los costos originados en ineficiencias no suelen tener consecuencias económicas automáticas sobre quienes deciden y ejecutan dicha provisión, lo que elimina los incentivos económicos para que tales combinaciones sean eficientes. Al contrario, en ausencia de un control eficaz del gasto por parte de quienes lo pagan - lo cual a su vez también tiene un costo- los intereses particulares pueden obrar más bien en el sentido opuesto: los riesgos de ineficiencia en la asignación pública se hacen evidentes sobre todo en los casos de corrupción política, principalmente en la adquisición de equipos e infraestructura inadecuados y/o sobrevalorados, y en la práctica del clientelismo. ${ }^{8}$

Es por eso que tanto las decisiones sobre provisión de bienes públicos como aquellas otras que se refieren a su producción y, entre estas últimas, particularmente aquellas que se refieren a la producción directa, implican riesgos para la eficiencia. Se suele denominar "ineficiencia asignativa" a la suma de las diferencias entre lo que cada ciudadano desearía obtener a cambio

\footnotetext{
7 Según analiza Kurer (1993).

${ }^{8}$ En el presente trabajo se utiliza el término "local" como antónimo de "central".
} 
de la parte de su ingreso que entrega para la provisión de bienes públicos, y lo que efectivamente recibe; e "ineficiencia productiva" a la diferencia, en términos de beneficio/costo, entre lo que se produciría con asignaciones de factores inducidas por la competencia económica y lo que efectivamente se produce a través de combinaciones de factores e insumos decididas a través de procedimientos político-administrativos. La ineficiencia técnica, al aumentar los costos, incrementa la ineficiencia asignativa.

\section{c) La descentralización como solución}

Desde el punto de vista económico, la descentralización es básicamente una reforma de la gestión pública dirigida a reducir ineficiencias en los procesos de asignación. Ella puede asumir dos formas fundamentales: i) descentralización política, que sería transferir la provisión de algunos bienes públicos a procesos democráticos locales, ${ }^{9}$ y ii) descentralización económica, que consistiría en transferir o exponer las decisiones sobre combinación de factores e insumos a la competencia económica. ${ }^{10}$

La descentralización política disminuiría la ineficiencia asignativa al adecuar la provisión de bienes públicos a preferencias geográficamente diferenciadas, reducir la complejidad de lo que se decide a través de procesos político-administrativos y facilitar la transparencia, la representación y la participación ciudadana; la descentralización económica, a su vez, mitigaría la ineficiencia técnica al introducir mecanismos de mercado en los procesos productivos, pero también contribuiría a aumentar la eficiencia asignativa, si reduce costos y disminuye el número de asuntos que deben ser objeto de decisiones político-administrativas. La descentralización política se vincula

\footnotetext{
${ }^{9}$ En Finot (2001) se analiza la evolución del concepto de descentralización en la región. El de "descentralización económica" que aquí se define ha sido desarrollado a partir del de Von Haldenwang (1990), que incluye tanto la privatización como la "desregulación", entendida esta última como la apertura de la producción a organizaciones no estatales, con y sin fines de lucro. Sin embargo, lo esencial de la descentralización económica sería esta última y no el cambio de propiedad, a que se refiere la privatización. Las principales formas de descentralización económica serían: compra de insumos (incluida la tercerización), concesión (transferencia de la producción de servicios manteniendo la propiedad de los activos) y convenio para provisión de bienes finales. En este último caso estarían las organizaciones privadas sin fines de lucro dedicadas a actividades científicas y a la producción de servicios de salud, consideradas por Bresser-Pereira (1998) como el "sector público no estatal", particularmente cuando son financiadas total o parcialmente con recursos públicos.

10 Gobernancia democrática: capacidad de una sociedad de gobernarse a sí misma (Espíndola, 1998).
}

directamente con una mayor gobernancia democrática; ${ }^{11}$ la descentralización económica, con una regulación que permita lograr un funcionamiento socialmente provechoso de los cuasimercados que conforma. ${ }^{12}$

De lo planteado anteriormente se desprende que para que la descentralización política contribuya a la eficiencia es necesario transferir poder de decisión no sólo sobre gasto local sino también sobre el aporte ciudadano para financiar dicho gasto. La generación de ingresos públicos se puede visualizar como contribuciones que los ciudadanos realizan a los distintos niveles de organizaciones territoriales del Estado a que pertenecen, niveles que, a su vez, atienden a distintos ámbitos de demanda. ${ }^{13}$ Para facilitar las decisiones sobre estos aportes, cada nivel debería contar con sus propias bases impositivas y poder modificar las respectivas tasas, a fin de que los ciudadanos, y sus representantes en cada nivel, puedan votar por soluciones alternativas con diferentes costos.

Tanto en el caso de la descentralización política como en el de la descentralización económica, el criterio básico para transferir decisiones de asignación es que los procesos descentralizados sean más eficientes que los centralizados. La condición, necesaria pero no suficiente, para el primer caso, es que la demanda esté territorialmente diferenciada — según ya se mencionó- y para el segundo, que sea posible la producción privada en competencia; pero la conditio sine qua non para que la descentralización - política o económicainduzca la eficiencia es que aumente la participación en los mecanismos de asignación: ciudadana, cuando se descentraliza la provisión; económica, si se descentraliza la producción. ${ }^{14}$

\footnotetext{
${ }^{11}$ Cuasimercados: la demanda se define políticamente mientras la producción se genera a través de la competencia económica. Por lo demás, mejorar el funcionamiento de la competencia económica hace parte del desarrollo de la gobernancia democrática.

12 Por tanto no sería adecuado afirmar, como se hace a veces, que un territorio genera la suma total de impuestos que sus ciudadanos pagan: estos últimos están contribuyendo a distintos ámbitos de soluciones cooperativas.

${ }^{13}$ Para algunos autores (Palma, 1985) el concepto de participación sólo debería referirse a los casos en que los participantes pueden influir efectivamente en las decisiones y por este motivo descartan la participación en el mercado. Esta afirmación, que es efectiva en lo que se refiere a provisión, no lo sería en cuanto a producción, ya que en este caso un ciudadano podría ejercer tanta o mayor influencia escogiendo entre productores alternativos que a través de una decisión política.

${ }^{14}$ Bienes colectivos: soluciones cooperativas generadas por organizaciones sociales, de las que se excluye a los no miembros. Los bienes que genera una organización social pueden ser bienes públicos en la medida en que benefician a todos los habitantes de un territorio - $-\mathrm{y}$ en este sentido se denominó "bienes públicos" en
} 
Por otro lado, lo esencial en los procesos de descentralización económica no sería la propiedad de los establecimientos productores sino el que éstos estén sometidos a la competencia económica. Así como muchas veces es conveniente privatizar, otras veces al hacerlo se puede destruir valioso capital institucional y social. Pero lo que sí sería importante para propiciar la eficiencia sería abrir las actividades productivas que no son exclusivas de las administraciones públicas a la competencia económica, eso sí, bajo una adecuada regulación.

\section{d) Importancia de la participación ciudadana}

Ya se ha mencionado que la descentralización política es la transferencia de la provisión de algunos bienes públicos cuya demanda está territorialmente diferenciada - bienes locales - a procesos democráticos que correspondan a esa demanda. Para asegurar eficiencia es imprescindible que las respectivas comunidades subnacionales puedan escoger libremente de qué bienes locales proveerse, en qué cuantía y con qué parte de su ingreso. El sujeto de la descentralización política, entonces, debería ser las comunidades subnacionales, mientras que sus respectivos aparatos gubernamentales no serían sino instrumentos para adoptar y ejecutar esas decisiones.

Desde un punto de vista económico, aumentar la participación democrática es mejorar el proceso de revelación de preferencias en las soluciones cooperativas. Por ello, la condición fundamental para que la descentralización política aumente la eficiencia en los procesos de asignación para la provisión de bienes públicos, sería que ella tendiera a igualar las oportunidades de participación y la representación de los intereses de todos los ciudadanos, en decisiones que afectan directamente sus ingresos actuales y futuros. Pero es evidente que, para que la participación democrática viabilice la revelación de preferencias y genere estímulos para el control social del gasto -y por tanto coadyuve a la eficiencia-, ella debe referirse al proceso completo de asignación, es decir, tanto al gasto como a los aportes que realizarán los ciudadanos para sufragarlo.

La participación ciudadana — directa e indirecta (Cunill, 1991) — puede ser política, si se refiere a las organizaciones territoriales del Estado integradas por órganos electos y a los partidos políticos, o social, si se

trabajos anteriores a los generados por las organizaciones sociales- pero, como bien observa Bresser-Pereira (1998), si se pueden excluir de su consumo a los no miembros de la organización que los genera, no son públicos (el autor mencionado llama a estos bienes "corporativos"). orienta a organizaciones sociales (asociaciones), según lo señalara Palma (1985). Pero estas últimas no sólo son medios de representación frente a las organizaciones del Estado sino además, y a veces principalmente, son medios de gestión de soluciones cooperativas, que a través de trabajo y aportes voluntarios con frecuencia no sólo proveen bienes colectivos ${ }^{15}$ sino también realizan importantes aportes a la provisión de bienes públicos ${ }^{16} \mathrm{o}$ generan significativas externalidades positivas para el interés público. ${ }^{17}$ La gestión del Estado, fundamentalmente a través de organizaciones territoriales de distinto nivel (nacional, intermedio, municipal, submunicipal), debería ser subsidiaria respecto a esta capacidad. Referirse sólo a "descentralizar el Estado" puede llevar a la idea equívoca de que para lograr los objetivos buscados basta descentralizar el aparato estatal cuando, bajo el principio de subsidiariedad, la descentralización de la gestión pública tendría que alcanzar hasta hacer a ésta subsidiaria respecto a las capacidades de las organizaciones sociales. Sin embargo, se debe tomar también en cuenta que todas ellas se organizan en torno a intereses particulares, según lo advierten Cunill (1991) y Bresser Pereira (1998), y una función insustituible de las organizaciones territoriales del Estado es velar porque el interés general prime sobre el particular, especialmente en lo que se refiere a la asignación de recursos públicos. ${ }^{18}$

La participación ciudadana en el proceso de provisión de bienes públicos y colectivos no sólo es un objetivo social ${ }^{19}$ y político fundamental, también es una condición esencial para reducir ineficiencias. Ahora bien: que los ciudadanos participen depende de que ellos perciban que el beneficio de participar es superior a su costo, y brindarles la oportunidad de participar en decisiones que afectan su ingreso actual y futuro podría contribuir decisivamente a concitarla. Para alcanzar esa condición es indispensable que la descentralización política no sea una simple transferencia de poder desde un centro a otros, sino que consista esencialmente

\footnotetext{
15 Por ejemplo mejoramiento de vías y otros espacios públicos.

16 Por ejemplo forestación, deporte, actividades culturales, seguridad ciudadana.

17 El apoyo estatal a estas organizaciones debe ser regulado en función del aporte de éstas a la provisión de bienes públicos, de las externalidades públicas que generan y de sus respectivos procesos de decisión. Sobre este último aspecto: el apoyo estatal a una organización en particular debería estar condicionado a que funcione democráticamente y ser directamente proporcional a la amplitud y grado de participación que convocan.

18 Principalmente en materia de salud mental.

${ }^{19}$ En este caso los gobiernos subnacionales actuarían como agentes del nivel central, con las ventajas y desventajas que han sido analizadas por Heymann (1988).
} 
en una reforma dirigida a inducir el involucramiento ciudadano en soluciones cooperativas (públicas y colectivas), siendo el límite de dicho involucramiento el punto donde las ganancias en eficiencia son iguales al costo económico de la participación.

Por otro lado, los procesos de descentralización política tienen que estar acompañados de sistemas de redistribución territorial dirigidos no solamente a reducir disparidades "iniciales" sino también a aminorar aquellas que la misma descentralización suscita al estimular la eficiencia. El problema está en encontrar los mecanismos que permitan asegurar equidad sin reducir los estímulos a la eficiencia. La forma de conseguir esto último sería que las transferencias del sistema central fueran estrictamente subsidiarias respecto a las iniciativas y los aportes locales, pero ello podría ser contraproducente en términos de equidad. Más adelante se presenta una propuesta para conciliar ambos objetivos.

\section{e) La descentralización operativa}

La descentralización política se refiere a la provisión de bienes locales pero, por otro lado, pueden existir algunos bienes para los que, aunque las decisiones sobre qué, cuánto y con qué recursos proveer sean adoptadas nacionalmente, resulte conveniente operarlas localmente y muchas veces no a través de administraciones desconcentradas sino de las administraciones de los gobiernos subnacionales. ${ }^{20}$ En estos casos los gobiernos subnacionales $-\mathrm{y}$ sus administraciones- ya no actúan como instrumentos de decisiones locales sino de decisiones nacionales, y la descentralización a que estos procesos dan lugar ya no sería política sino solamente operativa. ${ }^{21}$ Mientras en el primer caso las decisiones y el financiamiento corresponden primordialmente a la comunidad local y por tanto los gobiernos subnacionales deben responder de su gestión, en primera instancia, a la comunidad que los elige, en el segundo las decisiones se ejecutan por cuenta del nivel superior - que también debería hacerse cargo del financiamiento- y en este caso corresponde rendir cuentas en primera instancia a la comunidad mandante, que es la de nivel superior, representada por su respectivo gobierno. ${ }^{22}$

\footnotetext{
${ }^{20}$ En consecuencia, para que exista descentralización política no es suficiente elegir gobiernos locales. Sólo la hay en la medida en que se decida autónomamente la provisión de bienes locales.

${ }^{21}$ Lo que no implica que en segunda instancia también deban responder a los ciudadanos de su comunidad local, ya que los ciudadanos en general son los destinatarios finales de todos los bienes públicos.
}

\section{La descentralización en América Latina}

\section{a) Los procesos}

Según se mencionó en la introducción del presente trabajo, históricamente en América Latina los procesos de descentralización tanto política como económica aparecen como una contratendencia respecto a una propensión, predominante anteriormente, a centralizar decisiones políticas y económicas en los gobiernos nacionales. Como una consecuencia de la crisis de la deuda — que también podría ser caracterizada como una "crisis del centralismo"- - ahora se tiende a transferir funciones de provisión de bienes públicos hacia gobiernos subnacionales, y de producción de bienes y servicios provistos públicamente, hacia la competencia económica. Se ha descentralizado hacia gobiernos subnacionales principalmente funciones de provisión de educación y salud y de infraestructura y servicios básicos, y se tiende a descentralizar económicamente la producción de infraestructura y servicios de transporte, la de servicios básicos y, más recientemente, la de seguros y servicios de salud.

Revisiones de los principales procesos de descentralización de la región (Finot, 1999 y 2001), efectuadas principalmente a partir de información y análisis generados por varios proyectos de la CEPAL, permiten concluir que aún no hay indicios significativos de que ellos hubieran generado una tendencia generalizada a la participación ciudadana, e incrementos importantes y persistentes en términos de eficiencia pública y reducción de la corrupción. En lo que se refiere a equidad, si bien la descentralización ha contribuido a ampliar la cobertura de los servicios sociales, en muchos casos ella ha dado lugar también a notables diferencias entre territorios en términos de infraestructura y equipamiento para la prestación de servicios sociales, e incluso en la calidad de estos servicios. Ni la descentralización política ni los sistemas de redistribución territorial que la acompañan han logrado reducir tendencias históricas a la concentración territorial del ingreso. En cambio sí hay indicios de que tales sistemas contribuyen a crear desequilibrios presupuestarios. Como conclusión, se puede afirmar que en América Latina la descentralización aún no ha generado, al menos no sosteniblemente, los objetivos esperados.

\footnotetext{
22 Véase un análisis más detallado sobre gasto autónomo y sistemas de transferencias en Finot (2001).
} 
b) Por qué no se han logrado los resultados esperados

La principal explicación de que aún no se haya logrado los resultados esperados en materia de participación y eficiencia — que según el marco conceptual desarrollado en el punto anterior serían los objetivos propios de la descentralización- estaría en que los sistemas básicos de transferencias territoriales prevalecientes en la región por lo general no están orientados a apoyar procesos de provisión de bienes públicos donde las decisiones descentralizadas sean adoptadas autónomamente sobre la base del aporte local. La descentralización política, entendida como la capacidad de las comunidades locales para proveerse de bienes públicos sobre la base de iniciativas y aportes propios, aún es escasa en la región. Tales condiciones sólo se dan en algunos territorios relativamente "ricos" —en la medida en que no requieren de transferencias- y en el caso de la infraestructura básica en México, donde se cuenta con transferencias de libre disponibilidad que aumentan en función del incremento en la recaudación tributaria local. ${ }^{23}$

Más frecuente sería la modalidad de descentralización política del gasto, que se basa en transferencias de libre disponibilidad no condicionadas a aportes locales. ${ }^{24}$ Esta modalidad predomina en Brasil (donde contemporáneamente la descentralización se enfoca primordialmente hacia los municipios) y en Argentina (cuyo proceso se orienta principalmente a los gobiernos provinciales), y se da en menor medida en los demás países, a través de sus sistemas básicos de compensación; pero, al no vincular el gasto con el aporte local, no introduce los mecanismos de eficiencia económica propios de la descentralización. La participación, cuando se da, se refiere sólo al gasto.

Los otros casos de descentralización, ya sea que estén orientados primordialmente hacia niveles intermedios o hacia el nivel municipal, se caracterizan por una mezcla entre descentralización política del gasto y descentralización operativa, tendiendo esta última a predominar. Ello ocurre así porque en la mayoría de los territorios las transferencias básicas están más o

\footnotetext{
${ }^{23}$ Denominada "descentralización dependiente" por Medici (1995). ${ }^{24}$ Principalmente a través de los fondos de inversión social, pero ocurre algo similar con múltiples programas de asistencia técnica y capacitación de diversas organizaciones públicas, con los que se pretende apoyar el desarrollo local. El conjunto de proyectos finalmente aprobados obviamente no coincide con las prioridades locales. En la medida en que el gasto local es discernido de esta manera, resulta poco menos que imposible que las comunidades subnacionales puedan ejecutar sus propias estrategias de desarrollo.
}

menos condicionadas según uso y en el caso de aquellas otras, complementarias, provenientes de fondos de desarrollo, se suele exigir un aporte "local" (que generalmente proviene de esas transferencias básicas) pero las decisiones son tomadas centralmente. ${ }^{25}$ Bajo esta modalidad la participación social, cuando se da, suele reducirse a identificar necesidades.

Finalmente, ninguno de los sistemas de financiamiento vigentes está encaminado a propiciar procesos autónomos donde los ciudadanos participen en decisiones no solamente sobre gastos sino también sobre sus respectivos aportes. En cambio, aún priman mecanismos político-administrativos centralizados: subnacionalmente bajo las dos primeras modalidades de descentralización identificadas (descentralización política y descentralización política del gasto), y nacionalmente bajo la tercera (combinación entre descentralización política del gasto y descentralización operativa), que suelen generar oportunidades de corrupción. Ello sería así incluso en el caso mencionado de México, ya que allí la descentralización política alcanza principalmente sólo al nivel intermedio y de gobiernos de grandes ciudades, y sólo llega débilmente a los niveles más próximos al ciudadano. Esta situación general explicaría que, en la región, aún no se haya logrado obtener, con la descentralización, resultados convincentes y sostenibles en materia de participación $\mathrm{y}$ eficiencia.

Por otro lado, la explicación de que el gasto descentralizado hubiera contribuido, en algunos países, a generar desequilibrios presupuestarios sería que los sistemas de transferencias con que se cubre la mayor parte de dicho gasto no son subsidiarios respecto a las iniciativas y los aportes locales. Esto se debería principalmente al gran peso que tiene el gasto social entre las competencias transferidas: ¿cómo condicionar transferencias que están destinadas primordialmente a reducir la pobreza a la generación local de recursos públicos?

\section{c) Una explicación fundamental}

Toda esta situación podría explicarse básicamente porque al descentralizar no se habría diferenciado

\footnotetext{
${ }^{25}$ Que el financiamiento se decida centralmente no significa que las comunidades subnacionales que cuenten con mayores recursos -incluso provenientes de sus respectivos ingresos fiscales- no contribuyan a un fondo central que tuviera esta finalidad. Por otro lado, en los territorios en que existen importantes diferencias entre ingresos personales, el impacto de los recursos disponibles podría ser acrecentado si se opta por subsidiar el consumo antes que la oferta, previo análisis beneficio/costo.
} 
nítidamente entre bienes locales, cuya provisión es conveniente que se dé subnacionalmente, y bienes nacionales, donde la descentralización, si alguna, debería ser primordialmente operativa. En efecto: mientras la demanda de infraestructura y servicios básicos es claramente diferenciable territorialmente, el derecho a acceder a determinados niveles de servicios de salud y educación sólo es diferenciable cualitativamente, ya que todo ciudadano tiene igual derecho a un mínimo asegurado por el Estado, independientemente de su lugar de residencia. Mientras la provisión de infraestructura y servicios básicos pudo ser objeto de una descentralización política completa, hasta los niveles más próximos al ciudadano, la de salud y educación debió haber sido descentralizada, en lo fundamental, sólo operativamente, ya que en este caso las decisiones sobre qué, cuánto y con qué recursos proveer son una responsabilidad primordialmente nacional. Sin embargo, a ambos tipos de bienes se les ha dado un tratamiento similar, ya que se financia su provisión descentralizada con sistemas de transferencias similares. Con estos sistemas no se logra introducir incentivos económicos para propiciar la participación en los procesos de provisión - y por tanto la eficiencia y la reducción de la corrupción - y tampoco se alcanza a reducir las desigualdades que la propia descentralización suscita.

Obviamente todo lo anterior ocurrió en los contextos históricos particulares de cada país, pero la descentralización es también una reforma instrumental respecto a estrategias de desarrollo, que es necesario ir evaluando y readecuando en función de los objetivos que se van planteando las sociedades. En el punto que sigue se deduce del análisis anterior algunos lineamientos que podrían ser útiles para este propósito.

\section{Elementos para reorientar los procesos}

\section{a) Un nuevo objetivo}

Históricamente, la descentralización hace parte de un proceso de adecuación de la gestión pública a un nuevo paradigma que aún se encuentra en construcción. A los anteriores objetivos de mejorar las condiciones de vida de la población, lograr una mayor equidad territorial y social y concitar una participación ciudadana constructiva, todo ello con una mayor eficiencia en la gestión pública, se añade ahora el de adecuarse a una economía global en que se requiere condiciones de competitividad no solamente de la macroeconomía y la microeconomía sino también de la mesoeconomía, ya que contemporáneamente también compiten terri- torios. La descentralización se hace más necesaria que nunca para lograr este nuevo objetivo fundamental, junto con los anteriores. Pero es necesario que además contribuya efectivamente a la sostenibilidad financiera. Ello podría lograrse si se reorientan los procesos a partir de la mencionada diferenciación entre la provisión de una canasta social — de la que harían parte la educación y la salud- y la de infraestructura y servicios básicos.

\section{b) Qué descentralizar}

Por un lado, las decisiones sobre estructura, niveles y financiamiento de una canasta de bienes y servicios a la que todos deberían tener iguales posibilidades de acceso, independientemente de su lugar de residencia, deberían ser (re)centralizadas, en lo fundamental, en el nivel nacional. El contenido y dimensión de esta canasta dependerían directamente de las posibilidades de financiamiento de cada país. ${ }^{26}$ En cambio, sería conveniente descentralizar una parte del contenido y, sobre todo, la operación de estas decisiones centrales, hacia gobiernos subnacionales - esto último principalmente hacia el nivel municipal - y la producción de los servicios hacia establecimientos en competencia.

En cambio, donde sí sería altamente conveniente la descentralización política, generando condiciones de plena autonomía ${ }^{27}$ para las comunidades subnacionales de distinto nivel, es en el caso de la provisión de infraestructura y servicios básicos, ya que en este caso la demanda sí está claramente diferenciada debido a factores físicos y de estructura productiva. En este caso sí sería conveniente profundizar la descentralización política hasta llegar a niveles muy próximos al ciuda-

\footnotetext{
${ }^{26}$ Un caso interesante de descentralización económica sería la experiencia colombiana en materia de salud (ver una descripción completa de este sistema, su fundamentación y una evaluación en Jaramillo (1999). En una evaluación más reciente, este autor recomienda reducir la intervención del nivel intermedio a funciones de control. Por otro lado, en la región hay consenso en la conveniencia de descentralizar los procesos de producción de educación hasta el nivel de establecimiento. Adicionalmente, Chile y Bolivia muestran resultados interesantes de someter a competencia la producción estatal de educación: el primero, con su educación subsidiada y, el segundo, con la importante participación de las Escuelas de Cristo, en ambos casos con financiamiento del Estado. Finalmente, Chile también es un caso de administración municipal exitosa de subsidios acordados centralmente.

${ }^{27}$ Obviamente, autonomía no significa soberanía: tal provisión debe realizarse con estricta sujeción a la normativa del nivel superior donde, sin embargo, se debería dejar amplio espacio para que la provisión descentralizada se adecue a las diferentes características locales.
} 
dano, a fin de que dicha provisión se adecue con precisión a esas demandas diferenciadas. Junto con esa profundización, se debería inducir a las comunidades locales de distinto nivel para que desarrollen sus propias estrategias de desarrollo territorial —desarrollo económico local y mejoramiento del hábitat- en forma autónoma, participativa, coordinada con los otros niveles y asociándose entre sí en función de las diferentes demandas. Para que ello ocurra, la distribución de tareas de provisión debería darse siempre bajo el principio de subsidiariedad y el proceso de planificación realizarse respetando la autonomía de cada nivel de abajo hacia arriba, estableciendo mecanismos de coordinación intergubernamental e incentivando explícitamente el asociativismo territorial.

Específicamente, las funciones en las que se debería profundizar la descentralización política, hasta llegar a los niveles que mejor correspondan a los respectivos ámbitos de demanda a fin de propiciar el desarrollo local, serían: el ordenamiento territorial; la organización y control de la prestación de servicios de utilidad pública; la provisión de infraestructura urbana, de transporte y de aprovechamiento de recursos hídricos; los contenidos de educación y salud, y el apoyo a la pequeña y la mediana empresa.

Para asegurar el logro de objetivos de participación y eficiencia, la aprobación del gasto local debería estar condicionada a una efectiva participación ciudadana en la definición del monto de los aportes - actuales y futuros - conque la correspondiente comunidad contribuirá para ejecutar dicho gasto. Facilitar la participación en el sentido planteado requeriría: i) que los distintos niveles cuenten con bases impositivas propias y que puedan modificar las tasas (al menos dentro de ciertos límites) y, a la vez, fijar topes para su endeudamiento; ii) modificaciones en los sistemas de representación, ${ }^{28}$ decisión, información y rendición de cuentas en las organizaciones del Estado, y iii) una normativa para que las organizaciones sociales vinculadas con el desarrollo territorial puedan incorporarse plenamente a la generación y gestión de soluciones cooperativas, desempeñando funciones tanto de provisión de bienes colectivos como de participación y representación para la provisión de bienes públicos.

\footnotetext{
${ }^{28}$ Por ejemplo, en las organizaciones territoriales del Estado, cuanto más próximo el nivel a los ciudadanos, mayor preponderancia debería dar el sistema electoral a la representación territorial respecto a la proporcional y hacer que los representantes de cada territorio tengan la obligación de informarse e informar a sus representados, a través de las organizaciones de estos últimos y de medios de comunicación.
}

c) Modificaciones en los sistemas de transferencias En correspondencia con la anterior diferenciación, sería necesario transformar los actuales sistemas de transferencias en dos sistemas redistributivos diferentes, ambos subsidiarios: uno social, dirigido a asegurar a todos los habitantes de un mismo país un acceso igualitario a la mencionada canasta social, y otro territorial, encaminado a apoyar decisiones autónomas participativas en cada nivel subnacional y a reducir desigualdades territoriales. Los gobiernos municipales operarían el sistema de redistribución social en calidad de agentes de los respectivos gobiernos centrales y los gobiernos subnacionales en general, en su calidad de cabezas de autonomías, tendrían la responsabilidad del ordenamiento territorial y de la concertación del desarrollo económico territorial y el mejoramiento del hábitat en sus respectivos ámbitos, sobre la base de las iniciativas y los aportes locales, pero contando además con los recursos que le correspondan del sistema de redistribución territorial. Es más: en lo que se refiere a provisión de servicios básicos, una parte importante de la demanda estaría garantizada por el sistema de redistribución social (subsidios para consumo de agua potable, electricidad, disposición de desechos, etc.).

Sin embargo, si bien para asegurar eficiencia sería conveniente la descentralización de las decisiones sobre los aportes ciudadanos, para asegurar equidad sería también imprescindible que el sistema de redistribución territorial tendiera a compensar no solamente las diferencias territoriales "iniciales" sino aquellas que la propia descentralización incentiva y ello, en lo posible, sin menoscabo de los mecanismos de eficiencia propios de la descentralización. Para que el sistema de redistribución territorial asegure eficiencia y equidad, y a la vez contribuya a la sostenibilidad financiera, las transferencias territoriales deberían ser de libre disponibilidad pero estar condicionadas al aporte local relativo de cada comunidad (Finot, 1996) y a que las decisiones tanto sobre gasto como sobre aportes locales actuales y futuros (endeudamiento) hayan sido adoptadas participativamente. El concepto de "aporte local relativo" significa que las contribuciones de cada comunidad deben ser medidas no en términos absolutos sino en relación con su respectivo ingreso territorial y/o su dotación de recursos. ${ }^{29}$

\footnotetext{
${ }^{29}$ Por ejemplo, si se adoptara tan sólo el criterio del ingreso, se podría hacer que las transferencias fueran directamente proporcionales a los niveles de pobreza de cada localidad, pero estableciendo que las destinadas a infraestructura y servicios básicos, aunque de libre decisión sobre el uso, estén condicionadas al aporte local relativo.
} 
Además, se debería considerar como impuestos pagados — “cuasi impuestos" propusimos en una oportunidad anterior- y por tanto aportes locales, a las contribuciones que los ciudadanos realizan, en trabajo, materiales y dinero, a través de sus organizaciones sociales, a la provisión de bienes públicos y a la generación de externalidades públicas positivas. El reconocimiento explícito de esos aportes representaría además un avance fundamental en términos de construcción de ciudadanía y podría contribuir en forma decisiva a reducir el estigma que actualmente representa recibir subsidios del Estado: dichos subsidios serían retribuciones a ciudadanos que contribuyen a la provisión de bienes públicos, muchas veces con una parte importante de sus ingresos. ${ }^{30}$

\section{d) Diferenciar entre provisión y producción}

Finalmente, sería conveniente distinguir claramente entre funciones de provisión de bienes públicos y de producción de estos bienes, y continuar la actual tendencia a la descentralización económica en todos los sectores pero acompañándola de un esfuerzo constante de regulación de los cuasimercados emergentes, en cuya aplicación los gobiernos locales deberían cumplir un papel relevante.

\section{e) Posibles resultados y viabilidad}

Profundizar la descentralización en la dirección planteada permitiría no solamente estimular y facilitar la participación ciudadana sino lograr una relación sinérgica entre desarrollo de la ciudadanía, eficiencia fiscal y equidad. Más aún: orientar la descentralización política hacia el desarrollo territorial, podría contribuir tanto a generar significativos avances en eficiencia global y competitividad como a aumentar la cohesión social y facilitar el mejoramiento de las condiciones de vida de los ciudadanos. Esto último se haría posible sobre la base de esfuerzos cooperativos, que contarían con apoyo solidario a través de sistemas redistributivos eficaces.

La descentralización, así planteada, implica una profunda transformación institucional, que algunos consideran poco viable en la región (Véliz, 1980). Sin embargo, en América Latina y el Caribe, junto a la cultura centralista, en cuya evidencia se apoyan las conclusiones del autor citado, coexisten e incluso se han desarrollado prácticas de autogobierno que restan validez a esas conclusiones. ${ }^{31}$ Lo esencial no sería la ausencia de culturas alternativas a la centralista sino el hecho de que la descentralización y particularmente la descentralización política que es un proceso de construcción democrática que afecta la distribución actual del poder y genera tensiones entre tendencias democratizadoras e intereses centralistas antiguos y nuevos. Casi siempre los grandes avances en descentralización fueron respuestas frente a crisis políticas y/o resultado de la determinación de políticos visionarios que contaron con amplio respaldo popular. Pero contemporáneamente, en una economía global en la que compiten territorios - en el sentido amplio que ahora tiene el concepto de territorio- la descentralización política sería, además, una condición indispensable para potenciar la competitividad. Ello la colocaría nuevamente en un lugar preponderante de la agenda política de la región. El aporte decisivo de los intelectuales puede ser elaborar estrategias viables para profundizar los procesos, que puedan ser aprovechadas en las coyunturas políticas adecuadas.

\section{Bibliografía}

Aghón, G. E. y G. Krause-Junk (1996): Descentralización fiscal en América Latina: balance y principales desafíos, Santiago de Chile, Comisión Económica para América Latina y el Caribe (CEPAL).

Aghón, G. E. y H. Edling (comps.) (1997): Descentralización fiscal en América Latina: nuevos desafíos y agenda de trabajo, LC/L.1051, Santiago de Chile, CEPAL.

\footnotetext{
${ }^{30}$ Así se pudo comprobar, por ejemplo, a través de varios talleres realizados por el autor en algunos municipios rurales de Chuquisaca (Bolivia): en promedio, cada pequeño propietario rural había contribuido a la construcción de algunas obras públicas, en proporción a su ingreso, 17 veces más que uno urbano, incluidos los impuestos territoriales pagados por este último.
}

Bresser-Pereira, L. C. (1998): La reforma del Estado de los años noventa: lógica y mecanismos de control, Desarrollo económico, vol. 38, $\mathrm{N}^{\mathrm{o}}$ 150, Buenos Aires, Instituto de Desarrollo Económico y Social (IDES).

Carciofi, R. (ed.) (1996): Desafios de la descentralización: educación y salud en Argentina y Chile, LC/L.950, Santiago de Chile, CEPAL/Fondo de las Naciones Unidas para la Infancia (UNICEF).

\footnotetext{
${ }^{31}$ Así lo demuestran, por ejemplo, no solamente el funcionamiento de múltiples organizaciones de base en toda la región sino la cultura federalista que caracteriza a Brasil desde su independencia del Imperio, cultura cuyo desarrollo ha conducido a su actual descentralización en dirección a los municipios y que ahora avanza hacia lo "público no estatal".
} 
CEPAL (Comisión Económica para América Latina y el Caribe) (1998): El pacto fiscal: fortalezas, debilidades, desafios, $\mathrm{Li}-$ bros de la CEPAL, $\mathrm{N}^{\circ} 47$, Santiago de Chile.

Cunill, N. (1991): Participación ciudadana: dilemas y perspectivas para la democratización de los estados latinoamericanos, Caracas, Centro Latinoamericano de Administración para el Desarrollo (CLAD).

Di Gropello, E. y R. Cominetti (comps.) (1998): La descentralización de la educación y la salud: un análisis comparativo de la experiencia latinoamericana, LC/L.1132, Santiago de Chile, CEPAL.

Espíndola, R. (1998): Gobernancia democrática y salud, trabajo presentado al Taller sobre Gobernabilidad y Gobernancia en Salud, Washington, D.C., Organización Panamericana de la Salud (OPS) 8 y 9 de diciembre.

Finot, I. (1996): Descentralización, equidad y participación en América Latina: una aproximación económica, Santiago de Chile, LC/IP/R.165, CEPAL/Instituto Latinoamericano y del Caribe de Planificación Económica y Social (ILPES).

(1999): Elementos para una reorientación de las políticas de descentralización y participación en América Latina, Reforma y democracia, $\mathrm{N}^{\circ} 15$, Caracas, CLAD.

- (2001): Descentralización en América Latina: teoría y práctica, serie Gestión pública, Nº12, LC/L.1521-P, Santiago de Chile, CEPAL/ILPES.

Heymann, D. B. (1988): Input Controls in the Public Sector: What Does Economic Theory Offer?, IMF working paper, $\mathrm{N}^{\circ}$ 59, Washington, D.C., Fondo Monetario Internacional (FMI).

ILPES (Instituto Latinoamericano y del Caribe de Planificación Económica y Social) (1998): Reflexiones sobre el desarrollo y la responsabilidad del Estado, LC/IP/L.154, Santiago de Chile.

Jaramillo, I. (1999): El futuro de la salud en Colombia. Ley 100 de 1993, cinco años después, Santafé de Bogotá, Fundación Fredrich Ebert de Colombia (FESCOL)/ Fundación para la Educación Superior (FES)/ Fundación Restrepo Barco (FRB)/Fundación Corona.

Kurer, O. (1993): Clientelism, corruption, and the allocation of resources, Public Choice, $\mathrm{N}^{\circ} 77$, Amsterdam, Países Bajos, Kluwer Academic Publishers.
Medici, A. C. (1995): Saúde: modelos de gestâo descentralizada: alternativas para o Brasil, en J. P. Velloso, R. C. De Albuquerque y J. Knoop (coords.), Políticas sociais no Brasil: descentralizaçao, eficiência e equiidade, Río de Janeiro, Instituto Nacional de Altos Estudos (INAE).

Mueller, D. C. (1984): Public Choice II, A Revised Edition of Public Choice, Cambridge, Massachusetts, Cambridge University Press.

Musgrave, R. and P. Musgrave (1992): Hacienda pública, teórica y aplicada, Madrid, McGraw-Hill Interamericana.

North, D. (1993): Instituciones, cambio institucional y desempeño económico, México, D.F., Fondo de Cultura Económica (FCE).

Oates, W. (1977): Federalismo fiscal, Madrid, Instituto de Estudios de Administración Local.

(1999): An essay on fiscal federalism, The Journal of Economic Literature, vol. 37, $\mathrm{N}^{\circ} 3$, Nashville, Tennesse, American Economic Association.

Ocampo, J. A. (1999): Fortalezas, debilidades y desafíos del pacto fiscal, Reforma y democracia, $\mathrm{N}^{\circ} 13$, Caracas, CLAD.

Ostrom, V., C. Tiebout y R. Warren (1961): The organization of government in metropolitan areas: A theoretical inquiry, American Political Science Review, $\mathrm{N}^{\circ} 55$, Nueva York, Johnson Reprint Corporation.

Palma, E. (1985): La descentralización de la política social: participación e intersectorialidad, Documento CPS, $\mathrm{N}^{\circ} 48$, Santiago de Chile, CEPAL/ILPES.

Samuelson, P. A. (1954): The pure theory of public expenditure, The Review of Economics and Statistics, vol. 36, $\mathrm{N}^{\circ} 4$, Cambridge, Massachusetts, Harvard University Press.

Tiebout, C. (1956): A pure theory of local expenditures, The Journal of Political Economy, vol. 64, $\mathrm{N}^{\circ}$ 5, Chicago, Illinois, The University of Chicago Press.

Véliz, C. (1980): The Centralist Tradition of Latin America, Princeton, New Jersey, Princeton University Press.

Von Haldenwang, C. (1990): Hacia un concepto politológico de la descentralización del Estado en América Latina, EURE, vol. $16, N^{\circ} 50$, Santiago de Chile. 